\title{
The uniform enterprise income tax reform in China
}

\author{
WANG Zeng-tao ${ }^{1}$, DAI Wu-tang ${ }^{2}$ \\ (1. School of Public Economics \& Administration, Shanghai University of Finance and Economics, Shanghai 200433, China; \\ 2. School of Economics, Zhongnan University of Economics and Law, Wuhan 430073, China)
}

\begin{abstract}
In China, the income tax of enterprise is very different between foreign funded enterprises and other domestic enterprises. It is believed that this discrimination is harmful to the entire economy. So there is a reform in the tax system to build a uniform enterprise income tax. This is a significant reform in China's tax system, so every decision about this have to count the cost and the benefit carefully. The author has introduced the Computable General Equilibrium (CGE) to simulate this new tax system and value its benefit and cost. There are two different models in the paper; they are of different assumptions and for different purposes. Model I is a static CGE model and model II is a Ramsey Dynamic model. The static model is mainly used for comparative static approach to examine how the tax reform will change the endogenous variables. According to the results of the model, more goods will be produced by both of the DFEs and FIEs after the tax reform in the medium and low tax effective tax rate situations. If the nominal tax rates decrease $24.24 \%$ (from $33 \%$ to $25 \%$ ), the enterprise income tax will only reduce $19.36 \%$ and the total tax revenue will only reduce $1.911 \%$. The dynamic model will concentrate on the costs and benefits during the transition. From the results of the model, a lower tax rate will increase the level of investment, capital stock, capital prices, wage rate and also the growth rates through transition. If the capital tax rates are changed gradually, the fluctuating of transition will be smoothed a little.
\end{abstract}

Key words: enterprise income tax; reform; CGE model

\section{Introduction}

In China, the income tax of enterprise was very different between foreign investment enterprises (FIE) and other domestic founded enterprises (DFE) before Jan. 1, 2008. It was a significant element for Chinese government to attract inflows of foreign direct investment (FDI). Admitted this strategy had accelerated Chinese economic grows in the past years, more and more people believe that this discrimination is harmful to the entire economy nowadays. So there was a reform in the tax system to build a uniform enterprise income tax in China.

\subsection{The enterprise tax before reform in China}

From 90s and Jan. 1, 2008 now, separate enterprise tax laws for foreign and domestic enterprises were enacted. "Provisional Regulations of the Peoples Republic of China on Enterprise Income Tax" which was implemented since January 1, 1994 is suitable for domestic enterprises and "Income Tax Law of the Peoples Republic of China for Enterprises with Foreign Investment and Foreign Enterprises” which is implemented since July 1, 1991 is suitable for FIEs. Under this system, although the nominal tax rate seems equal for all enterprises, the tax rate for DFEs is $33 \%$ and the tax rate of FIEs is $30 \%$ and with a $3 \%$ surcharges to the local governments, the effective tax rate differs

WANG Zeng-tao, Ph.D. candidate of School of Public Economics \& Administration, Shanghai University of Finance and Economics; research field: public finance and taxation.

DAI Wu-tang, professor of School of Economics, Zhongnan University of Economics and Law; research fields: the economic development of Chinese mainland and Hong Kong, Macao and Taiwan. 
greatly because there are far more tax preferences for FIEs then DFEs. If they are in special economic zones, national hi-tech industrial zones and national grade economic and technical development zones, they pay a reduced enterprise tax rate of $15 \%$. FIEs in coastal regions and all provincial capitals pay 24\%. FIEs also receive tax holidays with a full exemption for 2 years, a 50\% exemption for the next 3 years. In addition, local governments frequently exempt them form local surcharges. The taxable income can again be reduced if income is reinvested. There is also differential tax treatment of wages paid to employees between FIEs and other enterprises ${ }^{1}$. The effective tax rates of domestic are $25 \%$ and $15 \%$ is for FIEs. The tax burden of DFEs is $10 \%$ more than that of FIEs ${ }^{2}$.

The separate enterprise system is designed for the transitional period of Chinese Economy in the early 90s. The main purpose of this tax system is to attract the inflows of foreign direct investment (FDI) and solve the problem of lacking capital and foreign exchange reserve. We have to admit that this strategy is a key factor to the recent strong growth performance of large inflows of FDI in China. But as the time goes the situation changed and the shortcomings of this separated tax system are more and more obvious.

\subsubsection{The "Super-national Treatment" is against the principle of WTO and international rules}

"National Treatment" or the "Non-discrimination principle" is the basic principle of WTO. But in China, the FIEs have the "Super-national Treatment", the tax preferences they enjoyed is far more than DFEs. It is harmful to the DFEs and the national industry for they can not have the same scratch line of competition. This will cause lots of distortions in the market, and is obviously against the spirit of WTO.

\subsubsection{The irregular tax system causes many problems in tax collection}

Because the effective tax rate differs greatly, which is similar to the corporate firms and the non-corporate firms in America, a lot of firms will try to get their classification changed so that they can achieve the lower tax rates. And this is the reason of the existence of lots of fake FIEs in China ${ }^{3}$. As the development of economic globalization, the more and more Chinese enterprises can invest overseas and again invest at home. So how to distinguish between DFEs and FIEs is not so clear any more. This causes lots of tax erosion and also makes lots of abnormal company organizations.

1.1.3 The high nominal tax rate is not good to attract FDIs and will reduce the trust in the tax system

The nominal enterprise income tax rate for FIEs is 33\%, which is relatively high according to most of other

\footnotetext{
${ }^{1}$ The tax enterprise tax system can be found on any textbooks of China taxation laws. John Whalley and LI Wang made a summarize in their working paper: "the Unified Enterprise Tax and SOEs in China" This paper can be found at: http://www.nber.org/papers/w12899.

2 "The explanation on 'The Law of the Peoples Republic of China on Enterprises Income Tax (draft edition)'” JIN Ren-qing report on "the Chinese National People's Congress".

The effective tax rate of the enterprise tax is discussed by John Whalley and LI Wang's working paper: "the Unified Enterprise Tax and SOEs in China” The following is the discussing on their paper: Different sources provide different estimates which lie in these ranges. Effective tax rates will differ by the life of assets, location of investments and finance. See the articles from (1) Embassy of the People's Republic of China in the United States of America: in the article: "China to Unify Corporate Income Tax Systems", which says: "The actual income tax rate has remained at 14 percent for overseas-funded businesses, much lower than the 24 percent rate for domestic firms, since China formulated the preferential policy for overseas-funded enterprises in mid-1980s in a bid to lure foreign investment”. The article can be accessed at http://www.china-embassy.org/eng/gyzg/t231590.htm; (2) Hong Kong Trade Development Council: in "Drafting of Unified Enterprise Income Tax Completed” says: “At present, domestic enterprises in China are subject to a nominal income tax rate of $33 \%$ while the actual rates applied to FIEs and foreign enterprises range from $15 \%$ to 24\%”. The article can be accessed at http: //www.tdctrade.com/alert/cba-e0304a-2.htm. (3) Development Research Center of State Council, PRC (2006, in Chinese). In the article: “When Can We Unify Enterprise Income Tax?”, it says: “In 2004, domestic enterprises in China are subject to an actual income tax rate of $26.29 \%$ the actual rates applied to FIEs and foreign enterprises is just around 13.87\%\%” This article can be accessed at: http://www.drcnet.com.cn/temp/20061114/gylt_7.html; (4) Peoples Daily (in Chinese): in the article "Why Is It So Difficult in Unifying Enterprise Income Tax" says “According to experts' evaluation, while domestic enterprises in China are subject to an actual income tax rate of $23 \%$ the actual rates applied to FIEs and foreign enterprises is just around 10\%”. This article can be accessed at http://finance.people.com.cn/GB/1045/3860233.html.

${ }_{3}$ This can be seen at the web in Chinese: http://www.ctax.org.cn/rdzt/lshy/mtpl/t20070207_287125.htm.
} 
countries. In the contrary, the effective tax rate is $15 \%$ instead and this will do harm to the liability of the tax system and give a bad reputation of Chinese tax system.

1.1.4 The region based tax incentives is harm to the coordinate development of regions in China

The economy in eastern coastal regions is better than that of interior regions because of the geographical and historical factors. After the reform and open policy in China, the predominance of eastern coastal regions is enhanced, and the tax incentives make the disparity of the regional economy more serious. Most flows of FDI are in the coastal regions.

1.1.5 Tax incentives are not the key factor in the decision-making of investors

A strong evidence of this point of view is what happened in America. There are nearly no tax incentive for FDIs, but its scale of FDI is one of the top countries in the world.

To the contrary, Uruguay has not many FDI, although its tax on FDI is believed one of lowest countries in the world ${ }^{4}$.

\subsection{The unified tax reform in China}

The shortage of the separated enterprise income tax is more and more serious. So, in March 16th, the Chinese National People's Congress has passed "The Law of the Peoples Republic of China on Enterprises Income Tax (draft edition)”. This law was implemented since January 1, 2008. This uniform tax reform on the enterprises income mainly includes following aspects. (1) DFEs and FIEs will apply a unified enterprise income tax law; (2) Both enterprises will have an uniform and lower corporate income tax rates of 25\%; (3) They will have unified and standard tax deduction methods and standards; (4) They will also have the same standard of tax preferences polices. (5) The tax rate of small companies with little profits is $20 \%$. This means the effective tax rate of DFEs will be reduced and the effective tax rate of FIEs will be increased. ${ }^{5}$

The proposal of this tax reform is raised ten years before, but until recently, this proposal is become the reality. There are many doubts and suspicions which postponed the progress of this uniform reform. There are two essential doubts on this reform. One is the worrying on the retreat of FDI and lack of attraction of FDI after uniform, and the other one is afraid of the diminishing of government revenue.

\section{Overview of the model}

In order to simulate the new tax system and value its benefit and cost, the author introduced the CGE models. CGE models which are computer-based simulations, like laboratory experiments, have become a standard tool of empirical economic analysis. They compute how today's economy will look in the future as a consequence of a specified set of policy changes. ${ }^{6}$ Harberger (1962) had used a general equilibrium model to investigate the incidence of the corporate income tax. And Shoven and Whalley (1984) have developed this model using the applied general equilibrium. Nowadays, the CGE model can be run at the computer easily because of the software called GAMS (General Algebraic Modeling System). The models in this paper is modified from Rutherford, T. F's model in "The Standard IFPRI Model Implemented in MPSGE" (T. F. Rutherford, 2006) and "Modeling Economic Adjustment: A Primer in Dynamic General Equilibrium Analysis” (Lau M. I., A. Pahlke \& T. F. Rutherford, 1997) and also referred to lots of other articles.

\footnotetext{
${ }^{4}$ Ai Zhang, "A brief analyze to the reform of property tax of corporation—for the unification of the two tax systems for domestic and foreign corporations” Economic \& Trade Update, 04/2007.

${ }^{5}$ I got these information on the web site: http://finance.sina.com.cn/blank/lshebing.shtml.

${ }^{6}$ WTO Discussion Papers No.10 “Demystifying Modeling Methods for Trade Policy” CGE model's feature is discussed particularly.
} 


\subsection{Models feature}

In this section, the author presents the structure of the model used for the simulation. There are two models with different assumptions and are for different purposes. Firstly the author used a table to show the summary of the model feature. (See Table 1)

Table 1 Summary of model feature

\begin{tabular}{|c|c|c|}
\hline & $\mathbf{I}$ & II \\
\hline Main purpose of the model & Analyze the financial impact of the reform. & $\begin{array}{l}\text { Analyze the transition costs and benefits of } \\
\text { the impact of the tax reform }\end{array}$ \\
\hline Model type & Static CGE & Ramsey dynamic CGE \\
\hline $\begin{array}{l}\text { Basic features and } \\
\text { consumptions }\end{array}$ & $\begin{array}{l}\text { Goods from DFE and FID are imperfect substitutes } \\
\text { Firm-type-specific capital }\end{array}$ & Welfare maximization in infinite-horizon \\
\hline Economic agents represented & $\begin{array}{l}\text { Producers } \\
\text { Consumers } \\
\text { Government } \\
\text { Enterprises } \\
\text { Foreign } \\
\end{array}$ & $\begin{array}{l}\text { Producers } \\
\text { Investors } \\
\text { Consumers } \\
\text { Government }\end{array}$ \\
\hline Production & \multicolumn{2}{|l|}{$\begin{array}{l}\text { Nested CES production technology } \\
\text { Leontief for output from intermediate inputs }\end{array}$} \\
\hline Household consumption & \multicolumn{2}{|l|}{ Stone-Geary utility function(LES) or CES function } \\
\hline $\begin{array}{l}\text { Government consumption } \\
\text { demands }\end{array}$ & \multicolumn{2}{|c|}{$\begin{array}{l}\text { Assumption government spending is exogenous and allocated among goods and services in fixed } \\
\text { proportions base on benchmark value }\end{array}$} \\
\hline Labor supply & $\begin{array}{l}\text { Labor market is assumed to be in equilibrium } \\
\text { Labor mobility across sectors. } \\
\text { Total level of employment is exogenous }\end{array}$ & $\begin{array}{l}\text { Labor market is assumed to be in } \\
\text { equilibrium. } \\
\text { Labor mobility across sectors }\end{array}$ \\
\hline Capital supply & $\begin{array}{l}\text { Divided into domestic funds and FDI, perfect mobility } \\
\text { across sectors }\end{array}$ & Capital perfect mobility across sectors \\
\hline
\end{tabular}

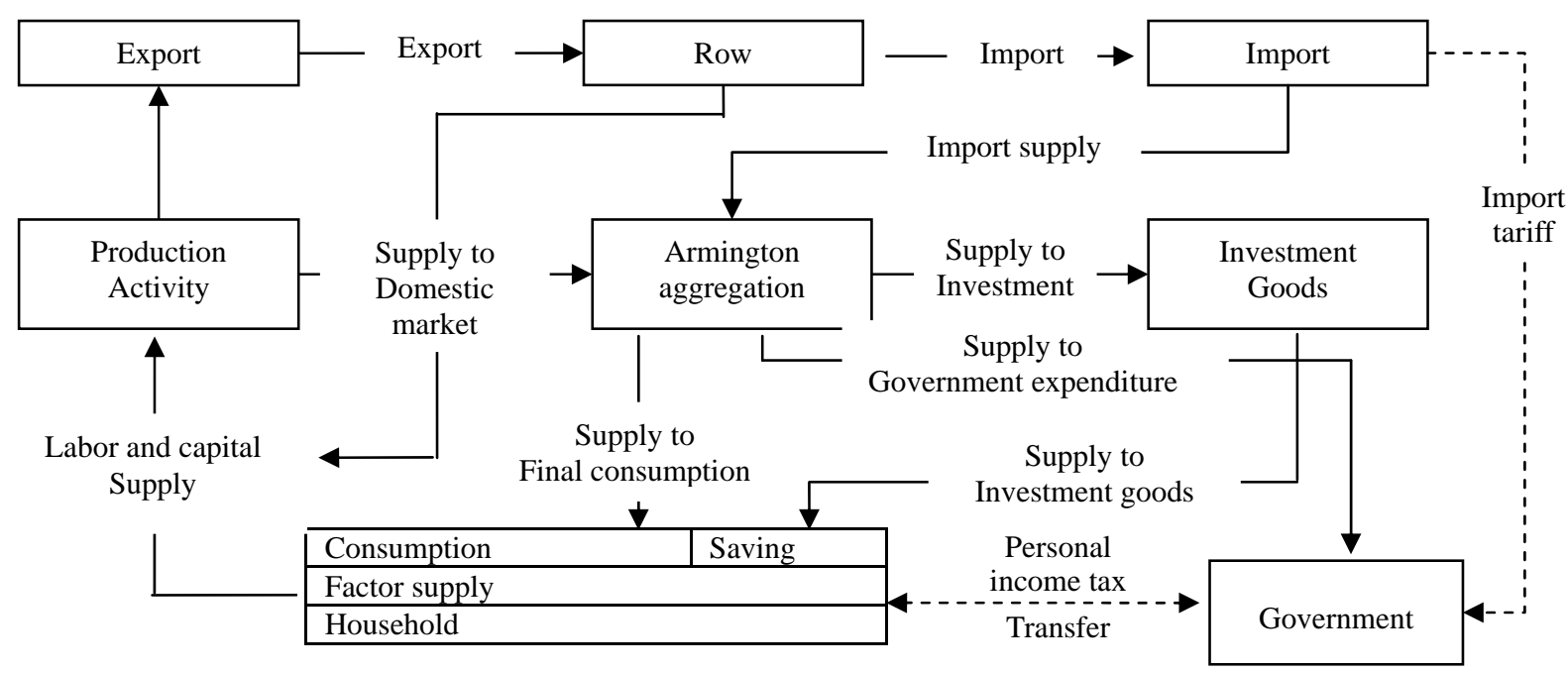

Enterprise Income tax (Capital tax) and Indirect tax on production

Fig. 1 Flow of goods, factors, taxes ${ }^{7}$

\footnotetext{
${ }^{7}$ For any CEG models is always having the same basic structure and flows of goods and factors and etc. So I made this figure and the following figures by revising the figures in Shiro Takeda’s paper: “The Double Dividend from Carbon Regulations in Japan” I adjust his figures to accommodate to my model. The structure of my article also refers to his paper.
} 


\subsection{Economic flows in the model}

The economic flows of my CGE model follows most general CGE models: Fig. 1 shows the flows of goods, factors and taxes in the model.

\section{The detail structure of the models}

\subsection{Production side}

Like the standard CGE model, using intermediate inputs and primary factors (labor and capital), firms produce goods under constant returns to scale (CRS) technology to maximize profits. All markets are assumed to be perfectly competitive.

Because of the data is limitation, the author have to assume that DFEs and FIEs characterized by the identical technologies. Under this assumption, it will be a trouble building a model which explains the coexistence of these two types of firms in the benchmark equilibrium. When the author follows the conventional CGE approach, the author can only get the corner solution. So, the author has too introduced some strategies in the model. The first one is differentiated outputs (goods from DFEs and FIEs are imperfect substitutes). The second one is the assumption of imperfect fact mobility. The third approach is the firm-type-specific factors, and this is an assumption in model I.

Production side under the assumption of differentiated outputs (Fig. 2):

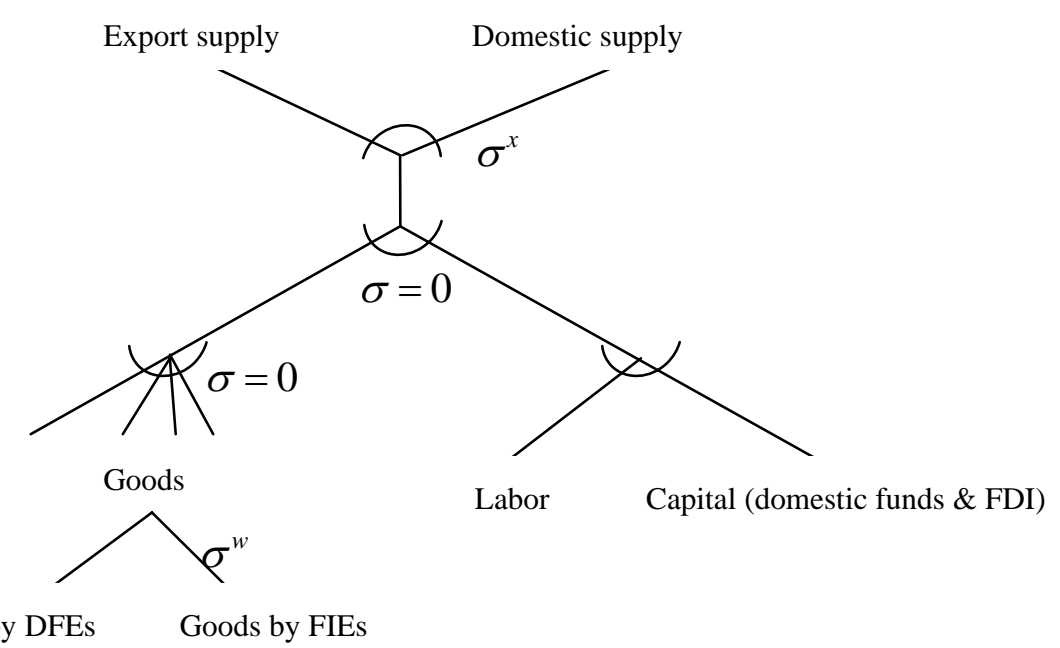

Fig. 2 Production side under assumption of imperfect substitute goods from DFE and FID

Intermediate inputs and aggregate value-added enter at the top level:

$$
Y_{s}=\min \left(\frac{I D_{s}}{a_{s}}, \frac{V_{s}}{b_{s}}\right)
$$

Goods from DFE and FID are imperfect substitutes in final and intermediate demand. Final demand and intermediate demand within each sector has a different share of DFE and FID goods. Goods are produced according to a nested CES (including Leontief-Cobb Douglas) technology.

$$
I D_{s}=\min \left[\frac{I D_{a g, s}}{a_{a g, s}}\right]
$$




$$
I D_{a g, s}=\left(\alpha_{g, s}^{d} I D_{d g, s}^{1+1 / \sigma^{w}}+\alpha_{g, s}^{f} I D_{f g, s}^{1+1 / \sigma^{w}}\right)^{1 /\left(1-1 / \sigma^{w}\right)}
$$

Value-added represents a Cobb-Douglas aggregation of labor, capital (including domestic found and FDI)

$$
V_{s}=L_{s}^{\alpha l} D K_{s}^{\alpha d k} F K_{s}^{\alpha f k} \quad(\alpha l+\alpha d k+\alpha f k=1)
$$

To develop a dynamic model (Model II), the author made a simplification of capital rent, that is

$$
K_{s}=D K_{s}+F K_{s} \text {, So } V_{s}=L_{s}^{\alpha l} K_{s}^{\alpha k} \quad(\alpha l+\alpha k=1)
$$

Each production sector produces types of commodities: domestic goods $D_{i}$ and goods for export $X_{i}$. These goods are assumed to be imperfect substitutes, and they have a constant elasticity of transformation. An algebraic formulation of this transformation function is written ${ }^{8}$ :

$$
Y_{s}=g\left(D_{i}, X_{i}\right)=\left[\alpha_{i}^{D} D_{i}^{1+1 / \sigma^{x}}+\left(1-\alpha_{i}^{D}\right) X_{i}^{1+1 / \sigma^{x}}\right]
$$

\subsection{Household}

A single representative agent (RA) is endowed with primary factors of production: capital, labor. The RA demands final goods for consumption. The level of consumption is endogenously-determined by utility maximizing behavior. The household utility function is Stone-Geary utility function as shown below:

$$
U=\sum_{s=t}^{\infty} \prod_{i=1}^{n}\left(C_{i}^{t}-b_{i}\right)^{a_{i}} \quad \sum_{i=1}^{n} a_{i}=1
$$

The household maximizes utility subject to a budget constraint:

$$
\max U\left(A_{i}\right)
$$

In static models:

$$
\text { s.t. } \sum_{t} p_{i} A_{i} \leq p_{d k} D K+p_{l} L+t r n-I
$$

In dynamic modes:

$$
\text { s.t. } \sum_{t} p_{i} A_{i} \leq p_{k} K+p_{l} L+t r n-I
$$

Under the assumption of differentiated outputs, household is a nested CES function in Fig. 3: Final consumption, saving, and labor supply are also derived from the optimizing behavior of this representative household.

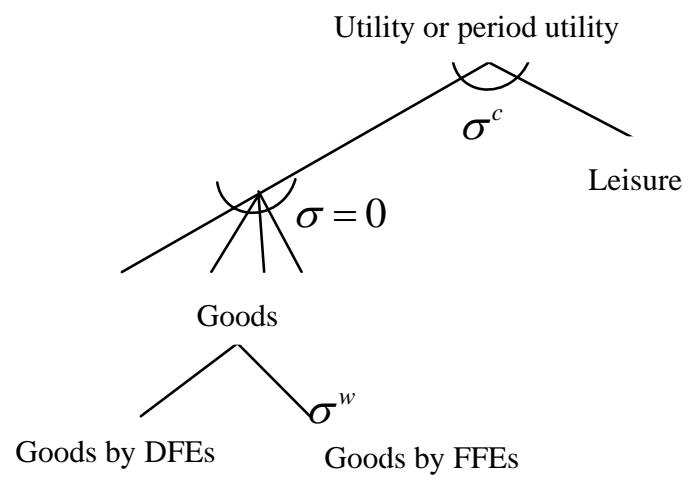

Fig. 3 Nested household utility

\footnotetext{
${ }^{8}$ This is the assumption in typical CGE models.
} 


\subsection{Armington aggregation}

Like other CGE analyses, we use the Armington assumption (Armington, 1969). The Armington goods are produced by combining domestic goods with imports from the same sector ${ }^{9}$.

$$
A_{i}=\left(\alpha_{i}^{M} M_{i}^{1-1 / \sigma^{a}}+\left(1-\alpha_{i}^{M}\right) D_{i}^{1-1 / \sigma^{a}}\right)^{1 /\left(1-1 / \sigma^{a}\right)}
$$

\subsection{Investment}

In the static model for the short run, investment demand is held constant at base-year levels. Investment funds come from households, government, enterprise and rest of the world.

In the dynamic models, capital accumulates as time passed. Current period's investment augments the capital stock in the next period. The aggregated capital stock at period $t+1$ is updated by an accumulation function equating the next-period capital stock at $t+1$ to the sum of the depreciated capital stock of the current-period and current-period's quantity of investment.

In dynamic Ramsey Model II, there are separate capital rental and purchase prices. The equation of motion for capital stock is given by:

$$
K_{s, t+1}=K_{s, t}(1-\delta)+I_{s, t}
$$

Because the real economic data is nearly impossible to be right in the steady-state growth path, I have to made several adjustments in Model II.

In the steady-state:

$$
I_{s, 0}=\frac{(\delta+g) K_{s, 0}}{\delta+r}
$$

$g$ is the growth rate of economic, $\delta$ is the capital depreciation rate and $r$ is the interest rate.

\subsection{Trade}

We assume that China is a small country and the world prices of goods are given constant. The real exchange rate is determined by supply of exports and demand for imports.

\subsection{Government}

$$
\sum_{g} \bar{p}_{g}^{E} X_{g}=\sum_{g} \bar{p}_{g}^{M} M_{g}+p_{k f} K F+p_{l} L_{r o w}+t r n
$$

The government obtains revenue by collecting taxes and debts (government deficit), which funds its expenditure. The taxes on production are corporation income tax (capital tax) and indirect tax. Labor tax is not on the production side and is based on the household's income.

\subsubsection{Expenditure of the government}

The expenditure of government includes "public expenditure", "transfer to household" and "transfer to rest of the world". Public expenditure indicates public demand and investment by government. Transfer to households is transfer such as social security contributions. Transfer to rest of the world includes aid to ROW and interest payment to ROW.

\subsubsection{Government income}

Government income is derived from taxes. There were various taxes in China. For example, there were corporation income tax, household income tax, value added tax, business tax etc. For it is extremely difficult to incorporate all existing taxes into a general equilibrium model which tries to capture the Chinese economy as a

\footnotetext{
${ }^{9}$ This is a typical assumption in most CGE models.
} 
whole, the author simply the model by divide existing taxes in China to the following four taxes: (i) labor income tax; (ii) enterprise income tax (capital tax); (iii) indirect tax on production; (iv) import tariff. Except for the enterprise income tax, the other taxes are simply use the traditional way of most CGE models.

Enterprise tax is looked as a capital tax on capital inputs at the production side. In some papers, capital tax and capital income tax was treated as different taxes. The tax base of capital tax is the capital input at the production side, but the capital income tax is based on the household (the capital owner) ${ }^{10}$ income, just like the labor income tax. But most of the researchers are looking the enterprise income tax as a capital income tax.

In my paper, the author used the enterprise income tax as a capital tax on capital inputs at the production side, this is a convenient way to simulate differential income tax rate between DFEs and FID.

There are two additional parameters in my enterprise tax block, which is turned the nominal tax rate into the capital income tax.

$$
t_{s}^{k}=t_{s}^{k n} \square \xi_{s}^{c} \square \xi_{s}^{l}
$$

In the above equation, $t_{s}^{k}$ is the real capital tax rate, which is calibrated with the benchmark data, $t_{s}^{k n}$ is the nominal tax rate, which is regulated by the laws of Chinese government. $\xi_{s}^{c}$ is the transforming coefficient, which transfer the capital income of sectors into the taxable income, which is the deduced after all the other parameters in the above equation. $\xi_{s}^{l}$ is the indicate of tax alleviate, which is estimated by experiences and the effect tax rate of searchers' finding.

\subsection{Market equilibrium}

In this section, equilibrium conditions for goods and factors markets are presented. In my models all the market is clear with the zero profits assumption. The price of the goods or factors will adjust to make all the market clear.

3.7.1 Market for goods

$$
M_{i}+D_{i}=\sum_{s} I D_{i, s}+C_{i}+G C_{i}+I_{i}+S T O_{i}+E_{i}
$$

$G C_{i}$ is the demand for public goods, $S T O_{i}$ is the change in stock.

\subsubsection{Market for factors}

Factor markets are perfectly competitive and full employment of all factors is assumed. The equation lists are as following:

$$
\sum_{s} L D_{s}=L E_{h}+L E_{f}, \quad \sum_{s} K D_{s}=K E_{h}+K E_{e n t}+K E_{f}
$$

\subsection{Restriction on terminal period}

This section is only for Ramsey dynamic model. Since we cannot solve numerically for an infinite number of periods, some adjustment are needed for approximation of finite horizon model to the infinite horizon choices. The author just follows the Rutherford's method.

$$
\frac{I_{t}}{I_{t-1}}=1+g
$$

$\mathrm{g}$ is the growth rate of $I$ in the steady-state which is an exogenous parameter.

\footnotetext{
${ }^{10}$ In Shiro Takeda's paper “The Double Dividend from Carbon Regulations in Japan” Jan, 2006, capital tax and capital income tax was treated as different taxes.
} 


\section{Data and parameters}

In this section, I will describe the benchmark dataset. I divided the benchmark data into three main parts: (1) Data in the SAM, (2) Elasticity data. (3) Other parameters. "Data in the SAM" are value data of outputs, intermediate inputs, primary factors, and final demand. These data refer to 2002, which is the benchmark year for the simulation. Elasticity data is the adjustment parameters in the computer. Other data refers to the parameters in enterprise income tax block, the depreciation rate, the growth rate of labor endowment, etc.

\subsection{Data in the SAM}

Like all the other CGE models, the Social Accounting Matrix (SAM) of 2002 is the starting point of the models. Table 2 shows the overview of China 2002 SAM. The data in the SAM is based on input-output table 2002 (Department of National Account, 2002) and miscellaneous yearbooks and literatures (Chinese Monetary Society, 2003; National Bureau of Statistics, 2003; Flow of Funds Table (2002); Financial Yearbook of China (2003).

Table 2 SAM for China 2002 (over view) (unit:100 million yuan)

\begin{tabular}{|c|c|c|c|c|c|c|c|c|c|c|c|c|c|c|}
\hline & Com & Act & L & K & H & E & Gvt & Inv & Stck & Dtax & Itax & Tar & Row & Total \\
\hline Commodity & & 193839 & & & 52225 & & 19116 & 43345 & 2550 & & & & 30913 & 341987 \\
\hline Activity & 314999 & & & & & & & & & & & & & 314999 \\
\hline Labor & & 58534 & & & & & & & & & & & & 58534 \\
\hline Capital & & 45264 & & & & & & & & & & & & 45264 \\
\hline Household & & & 58443 & 3377 & & 10471 & 495 & & & & & & 68 & 72855 \\
\hline Enterprises & & & & 40035 & & & & & & & & & & 40035 \\
\hline Government & & & & & & & & 3104 & & 3884 & 17362 & 2670 & 19 & 27039 \\
\hline Capital account & & & & & 19422 & 26887 & 7329 & & & & & & -4640 & 48998 \\
\hline Stock change & & & & & & & & 2550 & & & & & & 2550 \\
\hline Direct tax & & & & & 1208 & 2676 & & & & & & & & 3884 \\
\hline Indirect tax & & 17362 & & & & & & & & & & & & 17362 \\
\hline Tariff & 2670 & & & & & & & & & & & & & 2670 \\
\hline Row & 24317 & & 91 & 1852 & & & 100 & & & & & & & 26360 \\
\hline Total & 341987 & 314999 & 58534 & 45264 & 72855 & 40035 & 27039 & 48998 & 2550 & 3884 & 17362 & 2670 & 26360 & \\
\hline
\end{tabular}

\subsection{Sectors and estimated level of DFEs and FIEs}

There are 7 sectors in the commodity or activity account. The estimates level of DFEs and FIEs is shown in the Table 3. The author uses this data to divide each sector into the DFEs and FIEs. ${ }^{11}$

Table 3 Sectors and estimated level of DFEs and FIEs

\begin{tabular}{|c|l|c|l|}
\hline No & \multicolumn{1}{|c|}{ Sectors } & Percentage of DFEs & \multicolumn{1}{|c|}{ According to... } \\
\hline 1 & Farming, forestry, animal husbandry and fishery & $98.00 \%$ & Taxes levied on this sector and experiences \\
\hline 2 & $\begin{array}{l}\text { Mining, quarrying, manufacturing, electricity gas } \\
\text { water production \& supply }\end{array}$ & $70.70 \%$ & The output level \\
\hline 3 & Construction & $98.89 \%$ & The output level \\
\hline 4 & Wholesale and retail trade \& catering services & $94.40 \%$ & The investment level \\
\hline 5 & Finance and insurance & $98.86 \%$ & Business tax \\
\hline 6 & Real estate & $85.94 \%$ & The investment level \\
\hline 7 & Other sectors & $70.70 \%$ & The percentage of sector 2 \\
\hline
\end{tabular}

\footnotetext{
${ }^{11}$ It is some kind of subjective to divide the sectors into DFEs and FIEs of using the methods above. But it is the only way I have according to the available data.
} 


\subsection{Elasticity of substitution}

The following data is the parameters of substitution elasticity used in the model (Table 4).

Table 4 Value of elasticity parameters

\begin{tabular}{|c|l|c|}
\hline Notation & \multicolumn{1}{|c|}{ Description } & Value \\
\hline$\sigma^{x}$ & Elasticity of transformation between domestic supply and export supply & 4 \\
\hline$\sigma^{v}$ & Elasticity of substitution between capital and labor in sector s & 1 \\
\hline$\sigma^{a}$ & Armington elasticity of goods g & 0.4 \\
\hline$\sigma^{w}$ & Elasticity of substitution between DFEs and FIEs & 1.5 \\
\hline$\sigma^{c}$ & Elasticity of substitution between goods and leisure in households utility function & 1 \\
\hline
\end{tabular}

\subsection{Other parameters}

Parameters in enterprise income tax.

In the Table 5, capital tax rate is the real capital tax rate, which is calibrated with the benchmark data. The laws of Chinese government regulate the nominal tax rate. The transforming coefficient transfers the capital income of sectors into the taxable income, which is the deduced after all the other parameters in the above table. Indicate of tax alleviate, which is deduced by effective tax rate and the nominal tax rate. The effect tax rate is estimated and refers to searchers' finding and any information from Internet. ${ }^{12}$

Table 5 Parameters about enterprise income tax

\begin{tabular}{|l|c|c|c|c|c|c|c|c|c|c|c|c|c|c|}
\hline & \multicolumn{2}{|c|}{1} & \multicolumn{2}{|c|}{2} & \multicolumn{2}{|c|}{3} & \multicolumn{2}{|c|}{4} & \multicolumn{2}{|c|}{5} & \multicolumn{2}{c|}{6} & 7 \\
\hline & DFE & FIE & DFE & FIE & DFE & FIE & DFE & FIE & DFE & FIE & DFE & FIE & DFE & FIE \\
\hline Capital tax rate & 0.000 & 0.000 & 0.070 & 0.050 & 0.035 & 0.150 & 0.123 & 0.128 & 0.059 & 0.168 & 0.033 & 0.072 & 0.036 & 0.029 \\
\hline Nominal tax rate & 0.330 & 0.330 & 0.330 & 0.330 & 0.330 & 0.330 & 0.330 & 0.330 & 0.330 & 0.330 & 0.330 & 0.330 & 0.330 & 0.330 \\
\hline Transforming coefficient & 0.140 & 0.020 & 0.303 & 0.459 & 0.125 & 0.752 & 0.395 & 0.513 & 0.183 & 1.050 & 0.131 & 0.399 & 0.156 & 0.245 \\
\hline Indicate of tax alleviate & 0.006 & 0.003 & 0.697 & 0.333 & 0.848 & 0.606 & 0.948 & 0.758 & 0.978 & 0.485 & 0.758 & 0.545 & 0.697 & 0.364 \\
\hline Effective tax rate & 0.002 & 0.001 & 0.230 & 0.110 & 0.280 & 0.200 & 0.313 & 0.250 & 0.323 & 0.160 & 0.250 & 0.180 & 0.230 & 0.120 \\
\hline
\end{tabular}

Table 6 Parameters in dynamic models

\begin{tabular}{|c|c|c|}
\hline Notation & Description & Value \\
\hline g0 & Growth rate of economics & 0.08 \\
\hline r0 & Interest rate & 0.05 \\
\hline delta0 & Depreciation rate & 0.07 \\
\hline
\end{tabular}

These parameters (Table 6) are estimated from the experiences.

\section{Findings and concluding remarks}

\subsection{Shocks to sectors}

From the results of computations (See appendix, Table 8-Table 10), we can notice that:

(1) Except for the results from the high tax situation, both output of aggregate DFEs and FIEs will be increased. This is contrary to the common thoughts of most of people that the uniform tax reform is always

\footnotetext{
12 Effective enterprise income tax for finance and insurance: http://cn.biz.yahoo.com/06-03-/41/gkpj.html, others: http://finance.sina.com.cn/g/20061225/06233192669.shtml.
} 
decreasing the level of production of FIEs. So, if we have the tax reform and give the properly tax incentives, more goods will be produced by both of the DFEs and FIEs.

(2) The impact on sectors varies. From the results we can see some sectors production will both increase and others not. The DFEs and FIEs output in sectors of Farming, Construction, Real Estate will both increase. But in the other sectors the output of DFEs will increase but output of FIEs will decrease. Especially in the sectors of Manufacturing, Retail Trade and the Finance, the output of DFEs will be increased dramatically and FIEs will reduce to a certain amount. The main reason of these differences is the relative effective tax rate between DFEs and FIEs.

\subsection{Shocks to the revenue of taxation}

We can read from the results (See appendix, Table 11), in all of the three situations the total tax revenue will be reduced. But the level of reducing is not so serious according to the common view of points. In the high enterprise income tax situation, the nominal tax rate is decreased by $24.24 \%$ (that is from $33 \%$ to $25 \%$ ), but the total revenue from enterprises only reduced $19.36 \%$. What's more, the tariff will increase significantly and indirect tax which is the main source of China's government will also be increased. Because of the factors mentioned above, the total tax revenue of the government will only be reduced a little proportion.

For the rapid growth rate of tax revenue in China (exceed 20\%), the reduction of tax revenue will be coved by the newly growing taxes effortlessly.

\subsection{Shocks to the other indicators}

According to the results of Table 11 (See appendix), we can see the GDP, welfare of households, export and import level and the aggregate labor demand will be increased to a certain proportion. The lower tax rate is the higher level will be reached. The suspicious of reducing the labor demand after reform have been moved according to the results of the model.

\subsection{The transition cost and benefit of the uniform tax reform}

\subsubsection{Sector production}

From the Fig. 7, Fig. 11 and Fig. 15 (See appendix), we can see that all of the three situations will increase the production level to a certain degree. The lower tax rate, the higher production level will be reaching eventually, the level of growth of sector production in low capital tax situation is nearly two times as that of in the high tax situation. And the suddenly impact on the FIEs is obvious, and will cost an immediately negative growth rate of FIEs, but if we change the effective tax rate gradually, the FIE's output level will reduce too but not so obviously.

\subsubsection{Consumption, investment and capital stock}

According to the figures, the consumption level in the three situations is just the same. The investment level and the capital stock will increase as the capital tax reduced. The gradually change of enterprise income tax rate will reduce the transition cost for the line of investment in the Fig. 12 is more even than that in Fig. 4 and Fig. 8 (See appendix).

\subsubsection{Capital prices and wage rate}

Capital prices will decrease as the tax rate increases, and the wage is more obviously. Changing gradually will smooth the fluctuating a little.

\subsubsection{Growth rates through the transition}

A lower tax rate will cause a higher transition growth rate. The high tax rate will enhance the fluctuating of growth rates. Changing gradually once again smoothes the fluctuating again. 


\section{References:}

Hans Lofgren, Rebecca Lee Harris \& Sherman Robinson. (2002). A standard computable general equilibrium (CGE) model in GAMS.

John Whalley \& LI Wang. (2007). The unified enterprise tax and SOEs in China. Nber working paper (No.12899). Retrieved from http://www.nber.org/papers/w12899.

Lau M. I., A. Pahlke \& T. F. Rutherford. (1997). Modeling economic adjustment: A primer in dynamic general equilibrium analysis. University of Colorado. Working Paper. Retrieved from http://debreu.colorado.edu/primer/paper.htm. A version of the paper also appears as: Lau M. I., A. Pahlke \& T. F. Rutherford. (2002). Approximation infinite-horizon models in a complementarity format: A primer in dynamic general equilibrium analysis. Journal of Economic Dynamics and Controlm, 26, 577-609.

Laurent Cretegny \& T. F. Rutherford. (2004). Worded examples in dynamic optimization: Analytic and numeric methods. Retrieved from http://www.mpsge.org/dyn-optm.pdf.

Lofgren, H., R. L. Harris, S. Robinson, M. Thomas \& M. EL-Said. (2002). A standard computable general equilibrium (Cge) model in gams. Retrieved from http://www.ifpri.org/pubs/microcom/micro5.htm.

Markusen, J. R \& T. F. Rutherford. (1995). The Markusen examples. Notes for GAMS workshop. Retrieved from http://debreu.colorado.edu/markusen/markusen.htm.

Miles K. Light \& T. F. Rutherford. (2004). Taxation and economic efficiency in Armenia. Retrieved from http://www.mpsge.org/Armenia.pdf.

Roberta Piermartini \& Robert The. (2005). Demystifying modeling methods for trade policy. WTO discussion papers (No.10).

Rutherford, T. F. \& Miles K. Light. (2001). A general equilibrium model for tax policy analysis in Colombia. Retrieved from http://www.mpsge.org/dnp2001.pdf.

Rutherford, T. F. \& S. Paltsev. (2000). GTAP in GAMS and GTAP-EG: Global datasets for economic research and illustrative models. University of Colorado, Department of Economics Working Paper. Retrieved from http://debreu.colorado.edu/papers/gtaptext.html.

Rutherford, T. F. (1999). Applied general equilibrium modeling with page as a games subsystem: An overview of the modeling frame work and syntax. Computational Economics, 14, 1-2.

Rutherford, T. F. (2001). Calibration of models with multi-year periods. Retrieved from http://www.mpsge.org/time.pdf.

Rutherford, T. F. (2002). Lecture notes on constant elasticity functions. University of Colorado, Mimeo. Retrieved from http://debreu.colorado.edu/ces.pdf.

Sergey Paltsev. (2004). Moving from static to dynamic general equilibrium economic models (Notes for a beginner in MPSGE). Retrieved from http://www.mpsge.org/papers/newmove.pdf.

TAKEDA, S. (2007). The double dividend from carbon regulations in Japan. Journal of the Japanese and International Economies, 21, 336-364.

T. F. Rutherford. (2006). GTAP6inGAMS: The dataset and static model. Retrieved from http://www.mpsge.org/gtap6/.

The Chinese Institute of Certified Public Accountants. (2006). Taxation laws.

(Edited by Emily and Joy)

\section{Appendix: Results of computations}

\section{The shocks to the sectors}

One of the doubts which barriers the uniform tax reform is lots of authorities think the impacts on the FIEs will be too big. In order to value the impacts on FIEs, I used the above CGE model. After the enterprise income tax reform, the sector production will be changed. There are three situations in the simulation. The nominal tax rates in all three situations are equal to $24 \%$, and the transforming coefficient remains the same. But in the first situation, FIE’s indicate of tax alleviate adjust to the DFEs. This situation represents a relatively high capital tax rate on FIEs. In the second situation, the tax alleviate of DFEs remains the same but that of FIE's will be adjusted to the mean value of the original FIE's and DFE's. This represents a medium capital tax rate. In the last situation, all the tax alleviate will be changed to the mean value of the original FIE's and DFE's. Table 7 shows the effective enterprise tax rate in all sectors in the model. Table 8-Table 10 is the results of the simulation for impact on sectors.

Table 7 The effective tax rate in the three situations

\begin{tabular}{|c|c|c|c|c|}
\hline & Original & High & Medium & Low \\
\hline DFE_1 & $0.20 \%$ & $0.15 \%$ & $0.15 \%$ & $0.11 \%$ \\
\hline FIE_1 & $0.10 \%$ & $0.15 \%$ & $0.11 \%$ & $0.11 \%$ \\
\hline DFE_2 & $23.00 \%$ & $17.42 \%$ & $17.42 \%$ & $12.88 \%$ \\
\hline FIE_2 & $11.00 \%$ & $17.42 \%$ & $12.88 \%$ & $12.88 \%$ \\
\hline DFE_3 & $28.00 \%$ & $21.21 \%$ & $21.21 \%$ & $18.18 \%$ \\
\hline
\end{tabular}

(to be continued) 
The uniform enterprise income tax reform in China

\begin{tabular}{|c|c|c|c|c|}
\hline FIE_3 & $20.00 \%$ & $21.21 \%$ & $18.18 \%$ & $18.18 \%$ \\
\hline DFE_4 & $31.28 \%$ & $23.70 \%$ & $23.70 \%$ & $18.67 \%$ \\
\hline FIE_4 & $18.00 \%$ & $23.70 \%$ & $18.67 \%$ & $18.67 \%$ \\
\hline DFE_5 & $32.28 \%$ & $24.45 \%$ & $24.45 \%$ & $18.29 \%$ \\
\hline FIE_5 & $16.00 \%$ & $24.45 \%$ & $18.29 \%$ & $18.29 \%$ \\
\hline DFE_6 & $25.00 \%$ & $18.94 \%$ & $18.94 \%$ & $16.29 \%$ \\
\hline FIE_6 & $18.00 \%$ & $18.94 \%$ & $16.29 \%$ & $16.29 \%$ \\
\hline DFE_7 & $23.00 \%$ & $17.42 \%$ & $17.42 \%$ & $13.26 \%$ \\
\hline FIE_7 & $12.00 \%$ & $17.42 \%$ & $13.26 \%$ & $13.26 \%$ \\
\hline
\end{tabular}

Table 8 Shocks to sectors (high capital tax)

\begin{tabular}{|l|c|c|}
\hline \multicolumn{1}{|c|}{ Sectors } & DFE & FIE \\
\hline Farming, forestry, animal husbandry and fishery & $0.444 \%$ & $0.454 \%$ \\
\hline $\begin{array}{l}\text { Mining, quarrying, manufacturing, electricity gas water production \& } \\
\text { supply }\end{array}$ & $0.365 \%$ & $-0.287 \%$ \\
\hline Construction & $0.071 \%$ & $0.086 \%$ \\
\hline Wholesale and retail trade \& catering services & $0.305 \%$ & $-0.761 \%$ \\
\hline Finance and insurance & $0.176 \%$ & $-1.197 \%$ \\
\hline Real estate & $0.64 \%$ & $0.531 \%$ \\
\hline Other sectors & $-0.927 \%$ & $-0.454 \%$ \\
\hline Aggregate & $1.075 \%$ & $-1.628 \%$ \\
\hline
\end{tabular}

Table 9 Shocks to sectors (medium capital tax)

\begin{tabular}{|l|c|c|}
\hline \multicolumn{1}{|c|}{ Sectors } & DFE & FIE \\
\hline Farming, forestry, animal husbandry and fishery & $0.587 \%$ & $0.586 \%$ \\
\hline $\begin{array}{l}\text { Mining, quarrying, manufacturing, electricity gas water } \\
\text { production \& supply }\end{array}$ & $0.325 \%$ & $-0.063 \%$ \\
\hline Construction & $0.08 \%$ & $0.182 \%$ \\
\hline Wholesale and retail trade \& catering services & $0.349 \%$ & $-0.204 \%$ \\
\hline Finance and insurance & $0.31 \%$ & $-0.03 \%$ \\
\hline Real estate & $0.805 \%$ & $0.826 \%$ \\
\hline Other sectors & $-1.22 \%$ & $-0.574 \%$ \\
\hline Aggregate & $1.236 \%$ & $0.722 \%$ \\
\hline
\end{tabular}

Table 10 Shocks to sectors (low)

\begin{tabular}{|l|c|c|}
\hline \multicolumn{1}{|c|}{ Sectors } & DFE & FIE \\
\hline Farming, forestry, animal husbandry and fishery & $0.952 \%$ & $0.958 \%$ \\
\hline $\begin{array}{l}\text { Mining, quarrying, manufacturing, electricity gas water } \\
\text { production \& supply }\end{array}$ & $0.452 \%$ & $-0.117 \%$ \\
\hline Construction & $0.122 \%$ & $0.213 \%$ \\
\hline Wholesale and retail trade \& catering services & $0.51 \%$ & $-0.346 \%$ \\
\hline Finance and insurance & $0.367 \%$ & $-0.163 \%$ \\
\hline Real estate & $1.295 \%$ & $1.285 \%$ \\
\hline Other sectors & $-1.69 \%$ & $-1.16 \%$ \\
\hline Aggregate & $0.952 \%$ & $0.958 \%$ \\
\hline
\end{tabular}


The shocks to the other indicators under the same situations above:

Table 11 Shocks to the other indicators

\begin{tabular}{|l|c|c|c|}
\hline & High & Medium & Low \\
\hline GDP & 0.137 & 0.183 & 0.316 \\
\hline Welfare & 1.038 & 1.336 & 2.137 \\
\hline Export & 1.085 & 1.505 & 2.388 \\
\hline Import & 1.101 & 1.439 & 2.335 \\
\hline Labor demand & 1.079 & 1.364 & 2.137 \\
\hline Houshold income tax & -0.376 & -0.388 & -0.369 \\
\hline Enterprise income tax & -19.357 & -25.521 & -38.711 \\
\hline Tariff & 1.101 & 1.439 & 2.335 \\
\hline Indirect tax & 0.122 & 0.149 & 0.208 \\
\hline Total tax revenue & -1.911 & -2.524 & -3.814 \\
\hline
\end{tabular}

The indicators of transition with relative high capital tax rate:

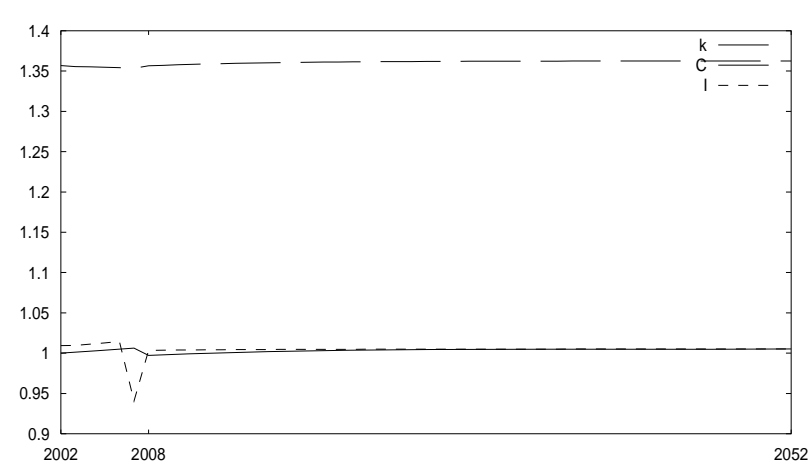

Fig. 4 Consumption investment and capital stock with high capital tax

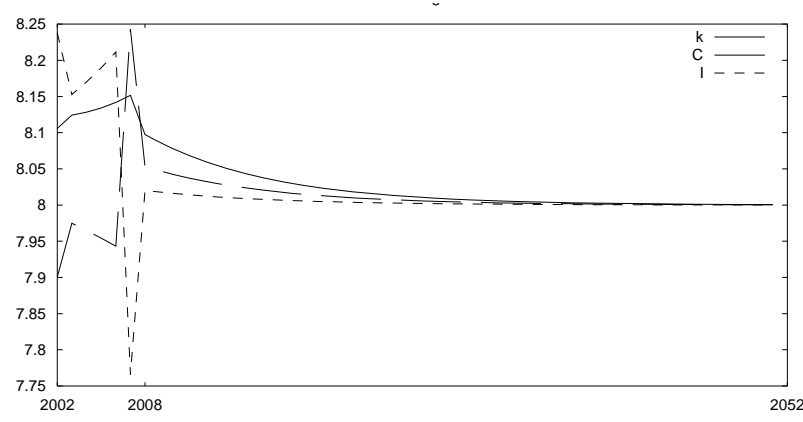

Fig. 6 Growth rate through the transition with high capital tax

The indicators of transition with relative low capital tax rate:

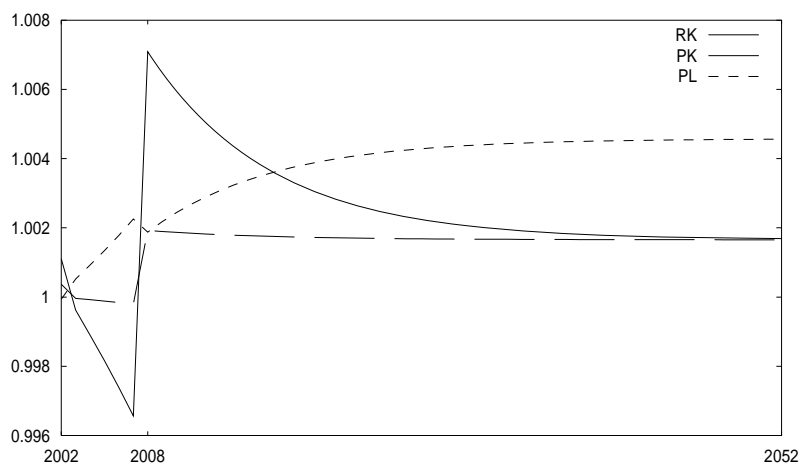

Fig. 5 Capital prices and wage rate with high capital tax

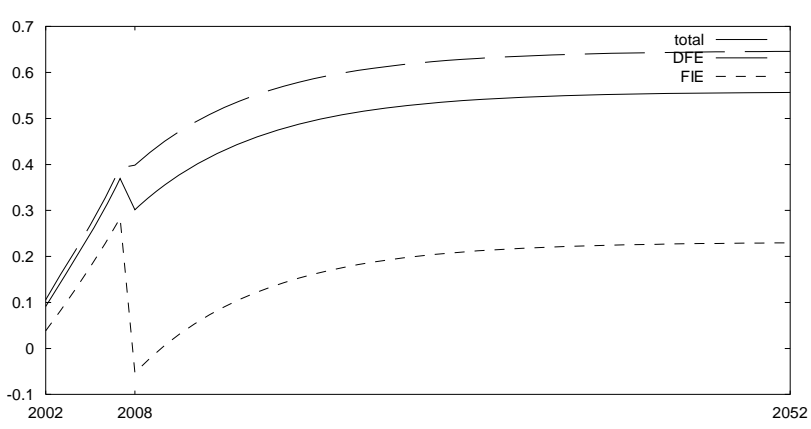

Fig. 7 Sector production with high capital tax 


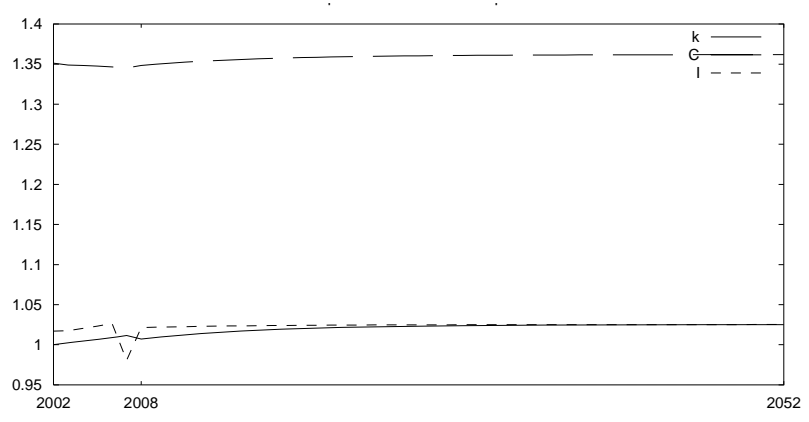

Fig. 8 Consumption investment and capital stock capital with low tax

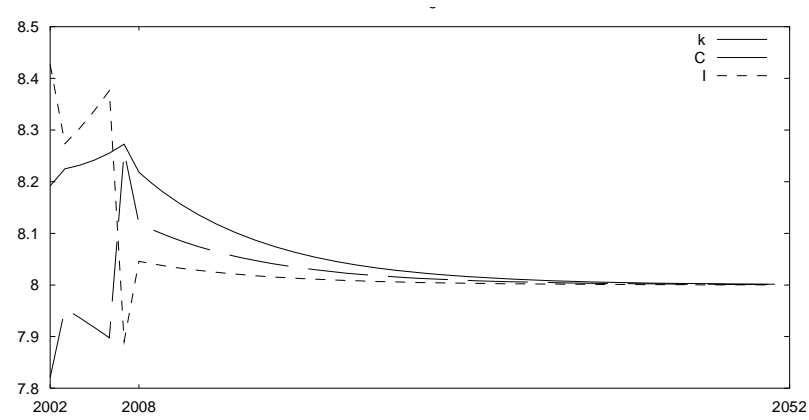

Fig. 10 Growth rate through the transition with low capital tax

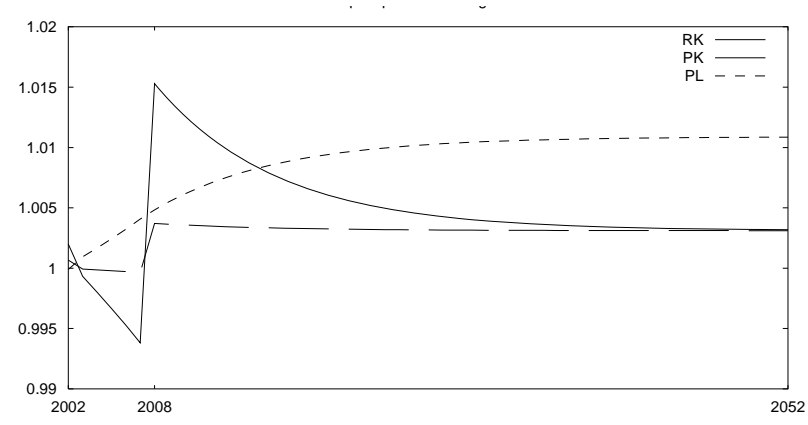

Fig. 9 Capital prices and wage rate with low capital tax

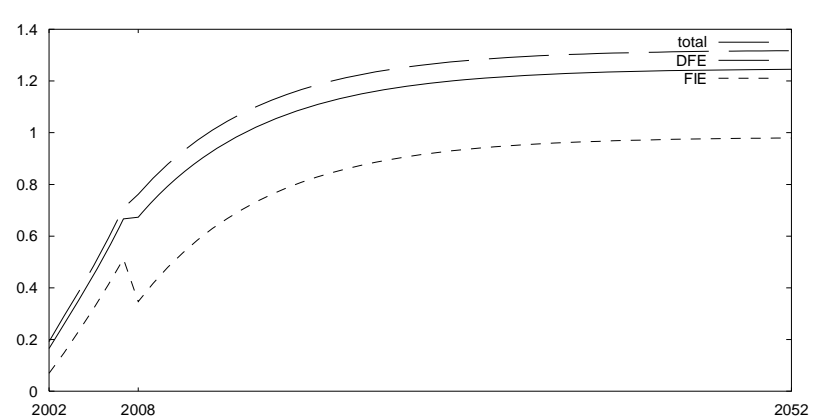

Fig. 11 Sector production with low capital tax

The indicators of transition with relative high capital tax rate but change gradually:

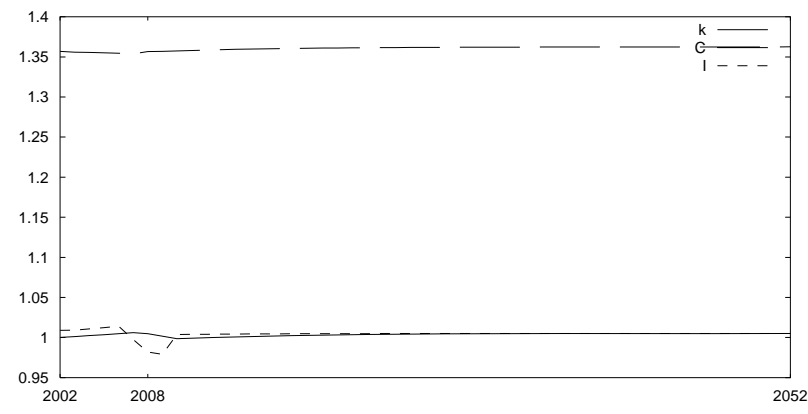

Fig. 12 Consumption investment and capital stock with gradually changing high capital tax

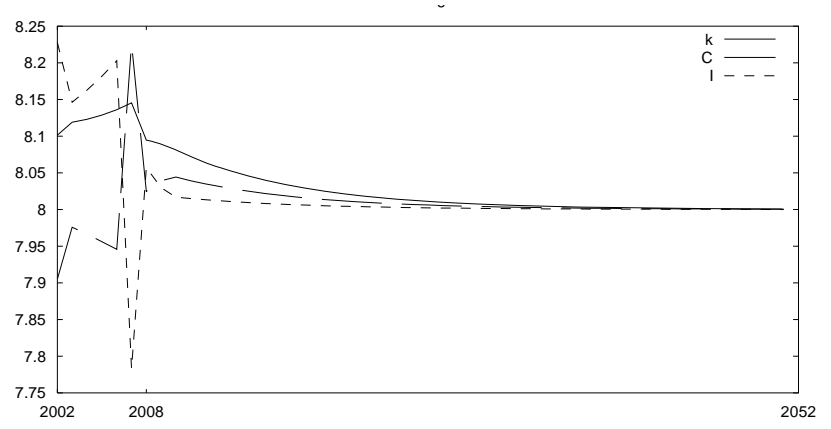

Fig. 14 Growth rates through transition with gradually changing high capital tax

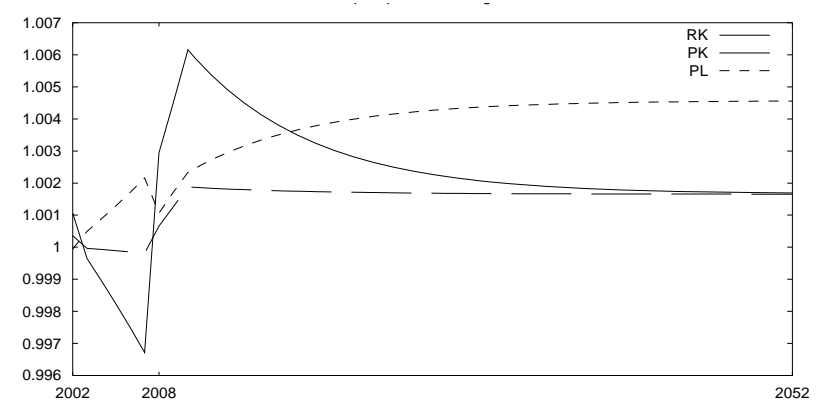

Fig. 13 Capital price and wage rate with gradually changing high capital tax

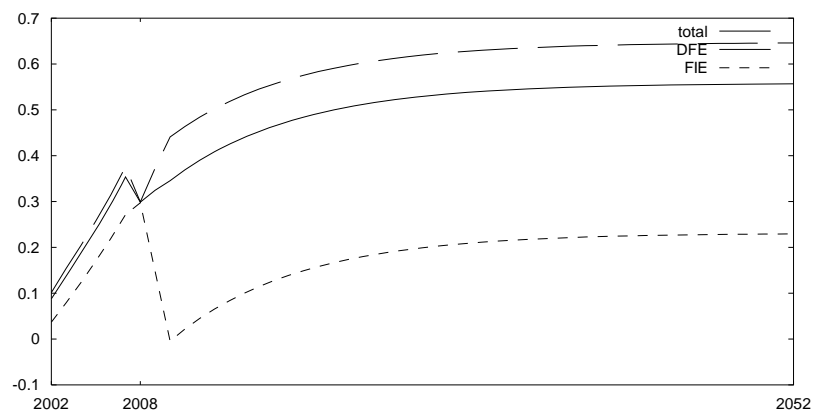

Fig. 15 Sector productions with gradually changing high capital tax 